\title{
Effect of afterload alterations on the functional border zone measured with two-dimensional echocardiography during acute coronary
} occlusion

\begin{abstract}
In the setting of acute myocardial infarction, pharmacologic intervention resulting in afterload changes are common but the effect of these changes on reglonal left ventricular function, and specifically the functional border zone, has not been fully investigated. Accordingly, we studied the effects of afterload manipulation on circumferential flow-function relationships and the functional border zone in 16 open-chest, anesthetized dogs. During left circumflex coronary artery occlusion, eight animals were infused with phenylephrine to increase afterload; eight others received nitroprusside for afterload reduction. Following coronary artery occlusion, subendocardial blood flow and wall thickening decreased in the ischemic zone $(p<0.001)$. The circumferential extent of hypoperfusion did not differ when coronary artery occlusion alone was compared to occlusion in combination with phenylephrine or nitroprusside, but in both groups the circumferential extent of the wall thickening abnormality was consistently greater than the extent of hypoperfusion. When blood pressure was decreased by $33 \%$, the extent of the functional border zone did not change relative to that during coronary artery occlusion (22 \pm 11 degrees vs $36 \pm 16$ degrees, $p=n s$ ). Similarly, when blood pressure was increased by $47 \%$, the extent of the functional border zone did not change ( $32 \pm 10$ degrees vs $37 \pm 10$ degrees). Therefore circumferential flow-function relations and the spatial extent of the functional border zone are not altered by changing afterload during acute left circumflex coronary artery occlusion in this model. (Am Heart J 1988;116:942.)
\end{abstract}

Kevin M. Kavanaugh, MD, Holly M. Brenner, BS, Kim P. Gallagher, $\mathrm{PhD}$, and Andrew J. Buda, MD. Ann Arbor, Mich.

Mechanical dysfunction in normally perfused myocardium adjacent to the ischemic area produced by coronary artery occlusion has been demonstrated in recent studies from our laboratories ${ }^{1,2}$ and from others. ${ }^{3.7}$ This region, identified as the "functional border zone," is characterized by nonischemic myo-

From the Cardiology Division, Department of Internal Medicine and the Departments of Physiology and Surgery, University of Michigan Medical School.

This work was supported in part by a grant-in aid from the American Heart Association of Michigan, Lathrup Village, Michigan, and by Grants HL 29716, HL 34691, and HL 32043 from the National Heart, Lung, and Blood Institute, National Institutes of Health, Bethesda, Md. Dr. Kavanaugh was supported by a Research Fellowship from the American Heart Association of Michigan. Dr. Gallagher is the recipient of NIH Research Career Development Award K04 HL 04120. Ms Brenner was a recipient of a Student Research Fellowship from the American Heart. Asanciation of ivichigan.

Received for publication Jan. 29, 1988; accepted June 1, 1988.

Reprint requests: Andrew J. Buda, MD, University of Michigan Medical Center, Cardiology Division, TC-3910, 1500 East Medical Center Dr., Ann Arbor, MI 48109-0366. cardium exhibiting diminished systolic wall thickening that extends approximately 25 to 30 degrees of the total left ventricular circumference from the ischemic interface on each lateral border into normally perfused muscle. ${ }^{1,2}$ Consequently, the size of the dysfunctional area is larger than that of the ischemic area. As a result, clinically applicable techniques, based on dynamic imaging (i.e., two-dimensional echocardiography, radionuclide angiography, nuclear magnetic resonance imaging, and ultrafast computed tomography) will tend to overestimate the size of acutely ischemic myocardium at risk. Additional distortion may occur if the size and severity of the functional border zone are altered by changes in hemodynamic conditions such as increases or decreases in afterload. Therefore the chjective of this study was to determine how changes in arterial blood pressure influence the lateral extent of nonischemic dysfunction during acute circumflex coronary occlusion.

In the setting of acute myocardial ischemia, 

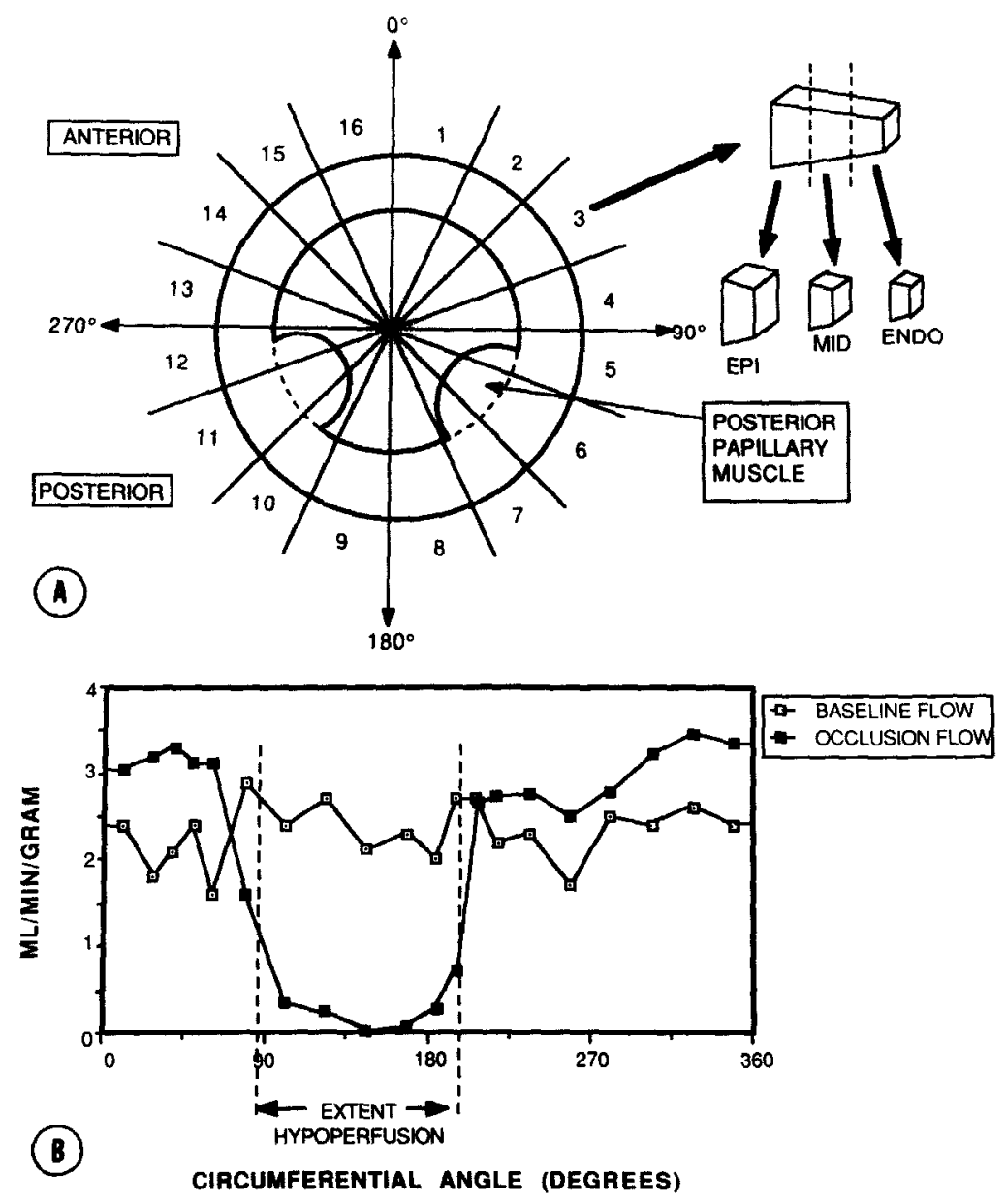

Fig. 1. Blood flow analysis. Schematic representation of our method for blood flow analysis is shown in A. Two sections of the left ventricle are taken at the level of the midposterior papillary muscle corresponding to the two-dimensional echocardiographic plane. Each slice is divided into 16 sections at 22.5-degree intervals, then further divided into endo-, mid-, and epicardial subsections for calculation of tissue blood flow. A representative subendocardial blood flow map is shown in B. Blood flow in milliliters per minute per gram of tissue is plotted against the circumferential extent of the left ventricle for each respective section of myocardial tissue. The extent of hypoperfusion during occlusion is defined by a $50 \%$ reduction of baseline blood flow.

changes in afterload are not uncommon. Examples include endogenously mediated increases in blood pressure along with pharmacologic decreases of afterload to improve global myocardial performance. The effect that such changes in afterload may have on circumferential flow-function relations and the functional border zone has not previously been studied with a clinically relevant technique such as two-dimensional echocardiography. Furthermore, since prognostic and therapeutic considerations may be based largely on assessment of nonischemic myocardial function, better understanding of how potential changes in the functional border zone are affected by fluctuations in afterload should be clinically important.
Alterations in afterload can have profound effects on left ventricular function, but few studies have addressed this issue specifically in terms of the functional border zone. With sonomicrometers, Sakai et al. ${ }^{8}$ and Gallgher et al..$^{9}$ observed that elevated afterload produced by aortic constriction produced uniform depression of wall thickening or segment shortening in nonischemic myocardium but little or no change in the functional border zone. However, neither study examined the effect of afterload reduction on functional responses. Our objective was to address these issues with a clinically applicable technique in a full cross-section of the left ventricle in order to obviate the limited sampling of regional function that constitutes a potential draw- 

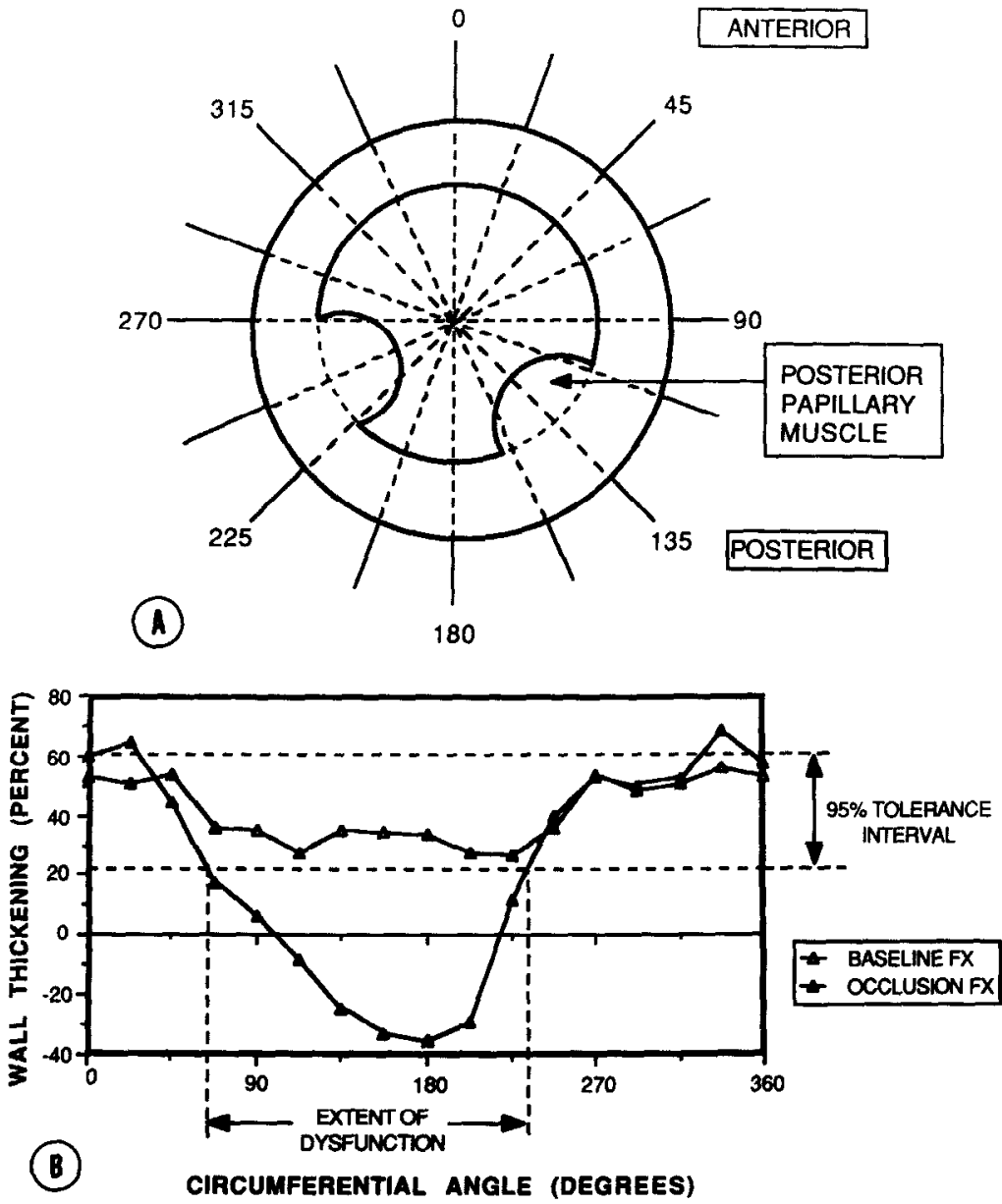

Fig. 2. Echocardiographic analysis. Schematic representation of our method for left ventricular function analysis is shown in A. Two-dimensional echocardiography is performed at the midposterior papillary muscle level. The endocardial and epicardial surfaces of the echocardiographic images are digitized and percent wall thickening is determined with a radial contraction method with an end-diastolic fixed center of mass. The midpoint of the posterior papillary muscle is assigned to 135 degrees to serve as an internal control. An example of a left ventricular function map is shown in $B$. The percent wall thickening is plotted against the left ventricular circumferential angle at each respective radius. Three consecutive heart beats are averaged to determine a normal range of wall thickening for each individual animal. Dysfunction is defined when wall thickening determinations fall below these $95 \%$ tolerance limits.

back of studies with sonomicrometers. Accordingly, we performed simultaneous two-dimensional echocardiographic and radioactive microsphere studies during afterload manipulation following acute coronary artery occlusion to construct circumferential flow-function maps. We designed a study to test the hypothesis that unloading the left ventricle with a vasodilator such as sodium nitroprusside during acute myocardial ischemia may improve flowfunction relations and reginnal dysfunction in the functional border zone. We also tested the converse hypothesis that increasing afterload with an agent such as phenylephrine may cause nonischemic regional function to deteriorate and the circumferential extent of the functional border zone to extend further into normally perfused myocardium.

\section{METHODS}

Animal preparation. Male mongrel dogs weighing between 20 and $30 \mathrm{~kg}$ were anesthetized with $10 \mathrm{cc}$ of thiamylal sodium followed by 2 cc of pentobarbital sodium, $6 \%$, intravenously. Additional pentobarbital sodium was administered during the experiment as necessary. The animals were ventilated on room air with a Harvard respirator (Harvard Apparatus Co., Inc., S. Natick, Mass.) via an endotracheal tube. A left lateral thoracotomy was performed in the fifth intercostal space, the lungs were retracted, and the heart was supported in a pericardial 


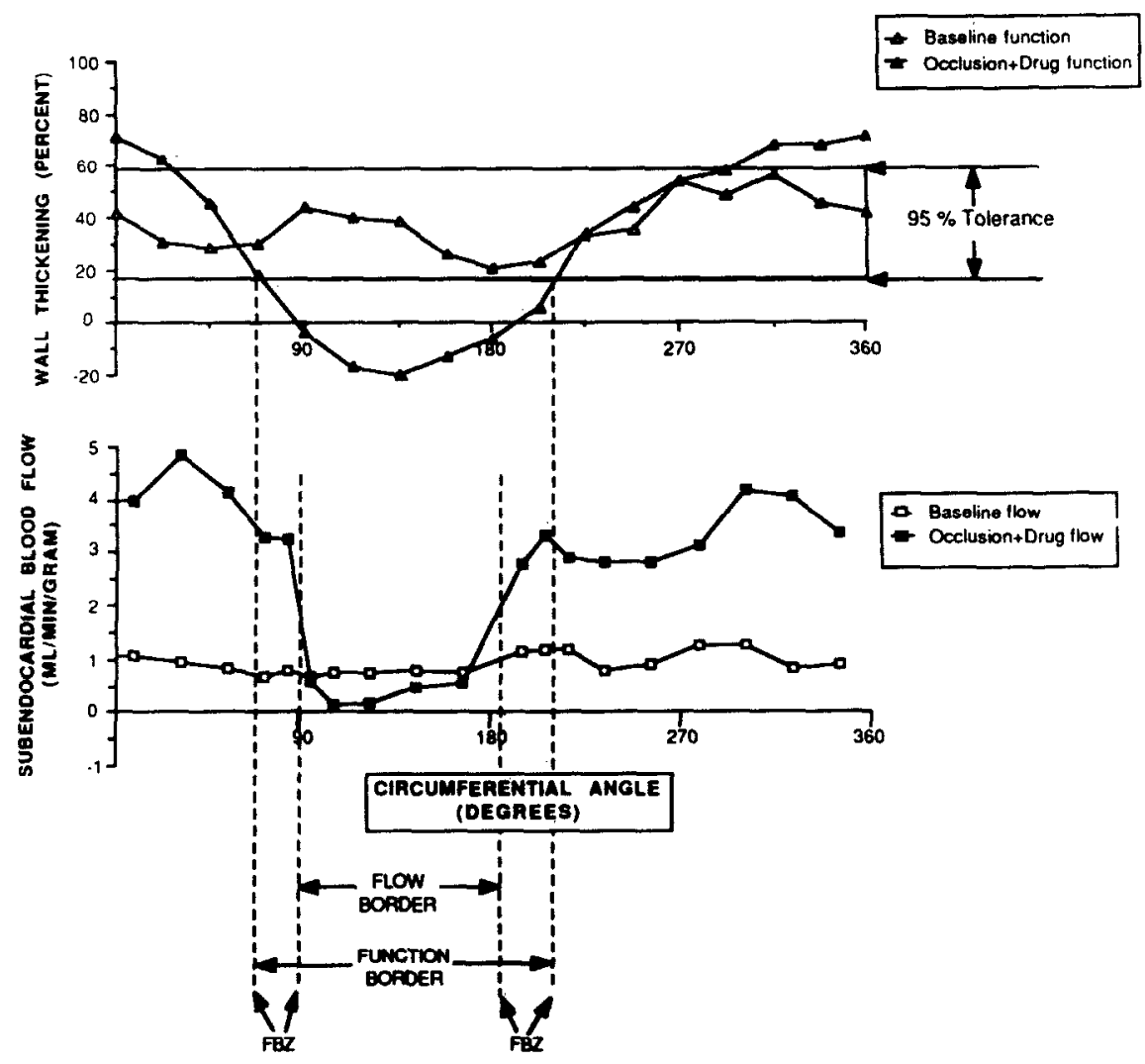

Fig. 3. Function and flow maps. An example of our method of determination of the extent of the functional border zones is shown here for one of the animals in the phenylephrine group. The upper part of this figure is the animal's unique function map, with the extent of dysfunction defined where wall thickening falls below this dog's $95 \%$ tolerance limits for normal function. The lower half of this figure contains the animal's subendocardial blood flow map. Abnormal flow is defined where perfusion is $50 \%$ or less than flow in the normally perfused regions of the myocardium. Note the marked increase in subendocardial blood flow in the normally perfused regions of myocardium compared to flow at baseline, prior to phenylephrine infusion. The extent of the functional border zone is the area in degrees where the functional abnormality overextends the perfusion abnormality as seen on the bottom of this figure. $F B Z$, functional border zone.

cradle. Polyvinyl catheters were placed into an internal jugular vein for fluid and drug administration, into the left atrium for injection of radioactive microspheres that were used to determine regional myocardial blood flow, and into a carotid and a femoral artery for hemodynamic monitoring and withdrawal of reference arterial samples. A segment of the left circumflex coronary artery was dissected free of surrounding tissues and a snare occluder was placed around the vessel proximal to the first obtuse marginal branch.

Experimental protocol. Sixteen dogs were studied, divided into two groups. Each group was studied sequentially in a nonrandomized design. The first group underwent coronary artery occlusion for a duration of approximately 40 minutes. After this period, phenylephrine $(0.1$ $\mathrm{mg} / \mathrm{ml}$ ) was infused at a rate of $0.8 \mathrm{ml} / \mathrm{min}$ for 3 to 5 minutes until mean arterial pressure increased approximately $30 \%$. The second group underwent coronary artery occlusion followed by infusion of $0.6 \mathrm{cc} / \mathrm{min}$ of $2.5 \%$ sodium nitroprusside until at least a $30 \%$ reduction in mean arterial pressure was noted. In both groups the left circumflex artery remained occluded throughout the experiment. Heart rate and blood pressure were recorded at baseline, during occlusion prior to drug infusion, and after the desired drug-induced changes in arterial pressure were manifest. Microspheres $(15 \mu \mathrm{m})$ in diameter, New England Nuclear, Du Pont NEN Medical Products, North Billerica, Mass.) labeled with cerium-141, chromium-51, strontium-85, niobium-95, or scandium-46 were injected into the left atrium for determination of regional myocardial blood flow with the reference withdrawal method. ${ }^{10}$ The microspheres were ultrasonicated and vortex agitated prior to injection. One to two million microspheres were injected over an 8- to 10-second period prior to occlusion, just before drug infusion, and when the desired druginduced blood pressure changes were attained. Concurrent with each microsphere injection, reference arterial blood samples were collected at a rate of $7 \mathrm{ml} / \mathrm{min}$ with a 
Table I. Hemodynamic and global left ventricular changes after coronary artery occlusion in 16 dogs (mean \pm SEM)

\begin{tabular}{|c|c|c|c|}
\hline & Control & Occlusion & $\begin{array}{l}\text { Occlusion }+ \\
\quad \text { drug }\end{array}$ \\
\hline \multicolumn{4}{|l|}{ Phenylephrine group } \\
\hline $\begin{array}{l}\text { Heart rate } \\
\quad \text { (beats } / \mathrm{min} \text { ) }\end{array}$ & $133 \pm 8$ & $128 \pm 8$ & $129 \pm 13$ \\
\hline MAP (mm Hg) & $105 \pm 7$ & $104 \pm 6$ & $153 \pm 6^{*}$ \\
\hline $\begin{array}{l}\text { LVED area } \\
\left(\mathrm{cm}^{2}\right)\end{array}$ & $9.6 \pm 0.7$ & $13.6 \pm 0.6 \dagger$ & $14.2 \pm 1.2 \dagger$ \\
\hline LVES area $\left(\mathrm{cm}^{2}\right)$ & $4.6 \pm 0.6$ & $9.5 \pm 0.7 \dagger$ & $10.0 \pm 1.3 \dagger$ \\
\hline LV area EF (\%) & $53.4+3.4$ & $31.1 \pm 2.7 \dagger$ & $31.5 \pm 4.9 \dagger$ \\
\hline \multicolumn{4}{|c|}{ Nitroprusside group } \\
\hline $\begin{array}{l}\text { Heart rate } \\
\quad \text { (beats } / \mathrm{min} \text { ) }\end{array}$ & $150 \pm 9$ & $156 \pm 8$ & $153 \pm 8$ \\
\hline MAP (mm Hg) & $135 \pm 10$ & $118 \pm 9$ & $91 \pm 8 \S$ \\
\hline $\begin{array}{l}\text { LVED area } \\
\left(\mathrm{cm}^{2}\right)\end{array}$ & $13.0 \pm 1.3$ & $14.1 \pm 1.2$ & $12.5 \pm 0.9^{*}$ \\
\hline LVES area $\left(\mathrm{cm}^{2}\right)$ & $7.1 \pm 1.0$ & $9.9 \pm 1.1 \dagger$ & $8.5 \pm 0.8$ \\
\hline LV area EF $(\%)$ & $47.0 \pm 2.8$ & $30.4 \pm 3.1 \dagger$ & $32.7 \pm 2.5 \dagger$ \\
\hline
\end{tabular}

$\mathrm{EF}=$ ejection fraction; $\mathrm{LV}=$ left ventricular, $\mathrm{LVED}=$ left ventricular end-diastolic; LVES = left ventricular end-systolic; $\mathrm{MAP}=$ mean arterial pressure.

${ }^{*} p<0.05$ compared to occlusion.

$\dagger p<0.01$ compared to control.

Harvard withdrawal pump (Harvard Apparatus Co., Inc.) starting 10 seconds before injection and continuing for 120 seconds after completion of the infusion.

Two-dimensional echocardiograms were obtained with a Diasonics 3400R scanner (Diasonics, Milpitas, Calif.) and a $2.5 \mathrm{MHz}$ transducer. The transducer was placed on the closed, shaved, right side of the chest. The chest thus served as a stand-off to allow full visualization of the circumferential extent of the left ventricle in the shortaxis projection. The left ventricle was scanned from the aortic valve to the apex in the short-axis projection and the midposterior papillary muscle position was identified. Images were obtained at the same time as microsphere injection and were recorded on a videocassette recorder for future analysis. Care was taken to perform echocardiograms and to inject microspheres during periods of normal sinus rhythm.

After completion of the experiment, the animals were killed with potassium chloride injection and the hearts were excised. The left ventricle was dissected free of surrounding tissue, cooled in a freezer for 15 minutes, and was then sliced into approximately eight sections ( 8 to 10 $\mathrm{mm}$ thick) perpendicular to the long axis. The slices were immersed in formalin for 2 to 5 days to facilitate subsequent sectioning.

Regional myocardial blood flow analysis (Fig. 1). Two unseculive iransverse slices of myocardium corresponding to the echocardiographic image at the level of the midpapillary muscle of the left ventricle were used for blood flow determinations. Each ring of tissue was sliced into 16 full thickness sections corresponding to the 22.5-
Table II. Subendocardial blood flows in 16 dogs

\begin{tabular}{|c|c|c|c|}
\hline & \multicolumn{3}{|c|}{ Blood flow $(\mathrm{ml} / \mathrm{min}$ per gram $\pm S E M)$} \\
\hline & Control & Occlusion & $\begin{array}{c}\text { Occlusion }+ \\
\text { drug }\end{array}$ \\
\hline \multicolumn{4}{|c|}{ Phenylephrine group } \\
\hline Normal zone & $0.98 \pm 0.10$ & $1.02 \pm 0.14$ & $1.87 \pm 0.38^{*}$ \\
\hline $\begin{array}{l}\text { Functional } \\
\text { border zone }\end{array}$ & $1.07 \pm 0.12$ & $0.78 \pm 0.10$ & $1.37 \pm 0.22 \dagger$ \\
\hline $\begin{array}{l}\text { Central } \\
\text { ischemic zone }\end{array}$ & $0.96 \pm 0.09$ & $0.12 \pm 0.05 \ddagger$ & $0.20 \pm 0.08 \ddagger$ \\
\hline \multicolumn{4}{|l|}{ Nitroprusside group } \\
\hline Normal zone & $1.66 \pm 0.21$ & $2.15 \pm 0.33$ & $1.34 \pm 0.12 \dagger$ \\
\hline $\begin{array}{l}\text { Functional } \\
\text { border zone }\end{array}$ & $1.65 \pm 0.21$ & $1.18 \pm 0.22$ & $1.07 \pm 0.07$ \\
\hline $\begin{array}{l}\text { Central } \\
\text { ischemic zone }\end{array}$ & $1.55 \pm 0.18$ & $0.15 \pm .04 \ddagger$ & $0.26 \pm 0.12 \ddagger$ \\
\hline
\end{tabular}

degree intervals used for echocardiographic analysis, as shown diagrammatically in the upper portion of Fig. 1. Full thickness sections in the vicinity of the perfusion boundaries produced by circumflex occlusion were cut into two smaller pieces to allow better delineation of the ischemic-nonischemic interface. Each section was further subdivided into epicardial, midmyocardial, and endocardial thirds. The samples were weighed and then placed in vials for radioactivity measurement in a Tracor 1185 gamma scintillation counter (Tracor Northern Inc., Middleton, Wisc.). Following background and overlap correction, absolute myocardial blood flow was calculated with the following equation: $Q_{m}=\left(C_{m} \times Q_{r}\right) / C_{r}$, where $\mathbf{Q}_{m}=$ myocardial blood flow (in cubic centimeters per minute), $C_{m}=$ counts $/ m i n$ in tissue sample, $Q_{r}=$ withdrawal rate of the reference arterial sample (in cubic centimeters per minute) and $\mathrm{C}_{\mathrm{r}}=$ counts $/ \mathrm{min}$ in the reference arterial sample. Blood flows per gram were calculated by dividing blood flow in each sample by its mass in grams. Circumferential blood flow maps were generated with a computer-assisted program, and a representative example is shown in the lower half of Fig. 1. Hypoperfusion was defined as a $50 \%$ reduction in subendocardial blood flow, ${ }^{13}$ and the circumferential extent of hypoperfusion was measured in degrees.

Echocardiographid analysis (Fig. 2). A minicomputerbased video digitizing system was used to select enddiastolic and end-systolic frames for analysis. ${ }^{11,12}$ The end-diastolic frame was selected with the use of the onset of the $\mathbf{Q}$ wave in lead II of the electrocardiogram (ECG). The smallest left ventricular cavity size was selected as a marker of end systole. The endocardial and epicardial borders for three consecutive heart beats were carefully traced by a blinded observer directly from the video display onto a digitizing tablet. Area ejection fraction was calculated as follows: [(end-diastolic area - end-systolic 


\section{OCCLUSION}

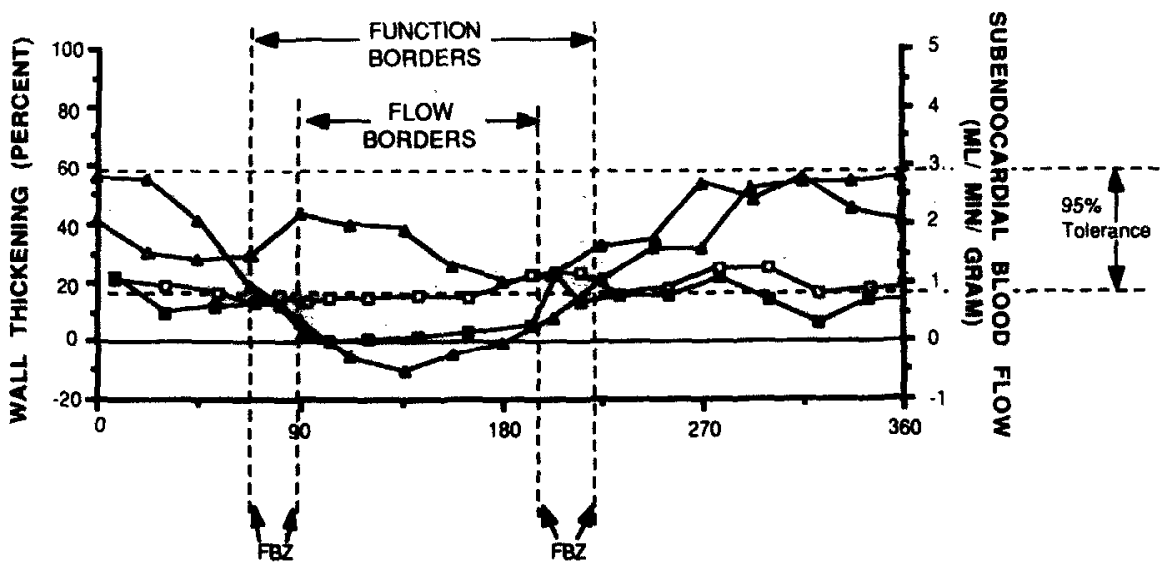

\section{OCCLUSION + PHENYLEPHPINE}

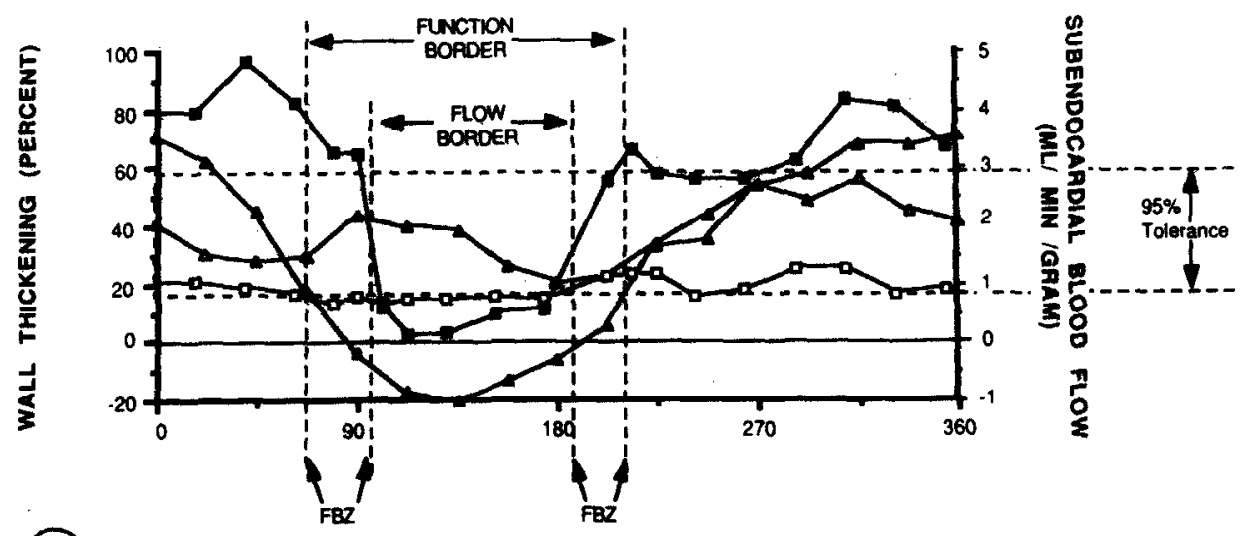

\section{(B)}

\section{CIRCUMFERENTIAL ANGLE (DEGREES)}

Fig. 4. Flow-function maps. Flow and function maps are superimposed to allow comparison of the extents of the functional border zone in this animal from the phenylephrine group. Note the similarity of the extent of functional abnormality relative to perfusion abnormality when comparing conditions during coronary artery occlusion (A) and coronary artery occlusion plus phenylephrine infusion (B). See also the legend to Fig. 3.

area)/end-diastolic area] $\times 100 \%$. Quantitative analysis of wall thickening was performed with a radial contraction model and a fixed diastolic center of mass at 22.5-degree intervals over the full left ventricular circumference and is represented graphically in Fig. 2, A. The midpoint of the posterior papillary muscle was designated as 135 degrees to correct for rotation and to serve as an internal landmark. Wall thickening was calculated for each of the 22.5-degree sectors by the following equation: [(endsystolic wall thickness - end-diastolic wall thickness)/ end-diastolic wall thickness] $\times 100 \%$. The mean $( \pm \mathrm{SD})$ percent wall thickening was calculated for three normal beats and $95 \%$ tolerance limits for normal were established for each animal. A unique functional map of the normal range was created for each dog. A representative example is presented in Fig. 2, B. Abnormally reduced systolic wall thickening, during occlusion or occlusion plus drug infusion, was defined by values less than the lower tolerance limit established during baseline conditions for each respective animal. The extent of dysfunction was 


\section{Phenylephrine}
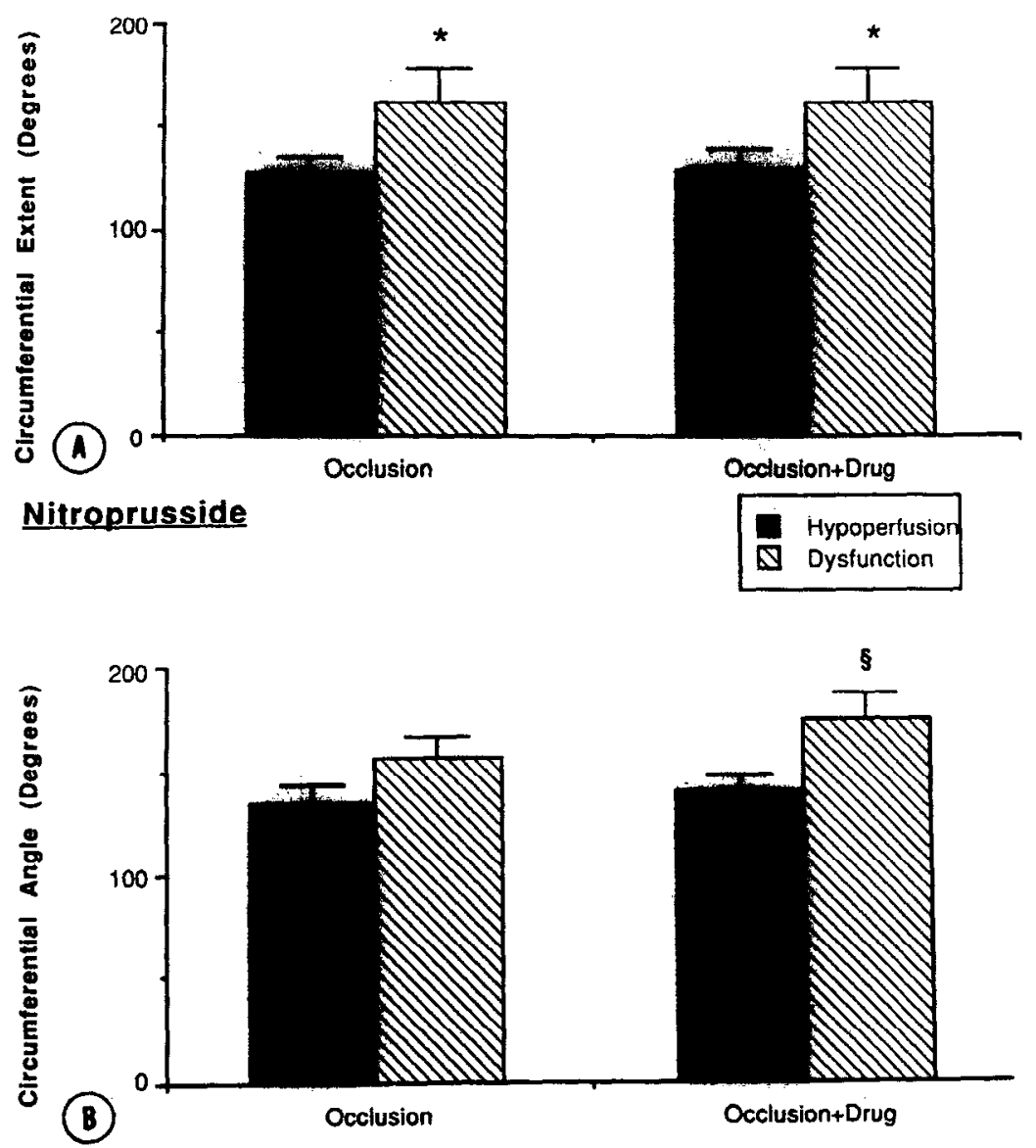

Fig. 5. Extent of hypoperfusion and dysfunction. The circumferential extent about the entire left ventricle of hypoperfusion and dysfunction are shown during occlusion and occlusion plus drug infusion for the phenylephrine group (A) and the nitroprusside group (B). ${ }^{*} p<0.05$ compared to hypoperfusion; ${ }^{* *} p<0.01$ compared to hypoperfusion.

measured as the circumferential distance between the intercepts of the occlusion (or occlusion plus drug) maps and the lower $95 \%$ tolerance limit and was expressed in degrees. The degree of dysfunction represented the area below the $95 \%$ tolerance limit as measured by planimetry and was expressed in square centimeters.

Data analysis (Fig. 3). Circumferential wall thickening maps were superimposed on the subendocardial perfusion maps for comparison of the extents of dysfunction relative to the extents of hypoperfusion, and a representative example is presented in Fig. 3. Geometric distortion related to fixation produced irregularities at the lateral borders of the flow-function maps in some animals. When this dictnrtion sciirson, the centers of the hypoperfused and dysfunctional zones were determined and the maps were generated laterally from these points. After generation of the appropriate flow-function map in each animal, the functional border zone was then defined as the absolute difference between the circumferential extent of dysfunction and the circumferential extent of hypoperfusion. ${ }^{14}$

Statistical analysis. All data are presented as mean \pm SEM. Comparisons within groups were made with a two-way analysis of variance. When significant $F$ statistics were obtained, paired $t$ tests were used to distinguish which time periods differed significantly. Because multiple comparisons were performed, the Bonferroni inequality adjustment was used to modify the acceptable alpha level. ${ }^{15}$ Comparisons between groups were made with an unpaired $t$ test.

\section{RESULTS}

Hemodynamic and global left ventricular function (Table I). There were no significant changes in heart rate among baseline conditions, coronary occlusion, 
and coronary occlusion plus phenylephrine or nitroprusside infusion. There were no significant changes in mean arterial pressure in either group when baseline and occlusion measurements were compared. However, with infusion of phenylephrine, mean arterial pressure rose $47 \%$ compared to baseline, which also was significantly higher than values at occlusion prior to drug infusion $(p<0.05)$. Mean arterial pressure decreased $33 \%$ with the infusion of nitroprusside during coronary occlusion $(p<0.01)$.

In the phenylephrine group, left ventricular enddiastolic area increased $42 \pm 6 \%(p<0.01)$ with occlusion and remained unchanged with infusion. In the nitroprusside group, baseline end-diastolic area did not differ from values during occlusion alone or with drug infusion. However, end-diastolic area with nitroprusside infusion was $11 \pm 6 \%$ less $(p<0.05)$ when compared to values at occlusion. A significant increase in left ventricular end-systolic area was noted in both groups when occlusion values were compared to baseline $(p<0.01)$. No further changes were seen with infusion of phenylephrine. With infusion of nitroprusside, however, end-systolic area improved to near baseline values. Global left ventricular area ejection fraction in the phenylephrine group fell with occlusion $(p<0.01)$ and did not change with drug infusion. In the nitroprusside group, area ejection fraction also fell significantly with occlusion $(p<0.01)$ and there was no significant improvement in area ejection fraction with drug infusion.

Regional blood flow (Table II). At baseline, subendocardial blood flows were similar in all regions. Following occlusion, subendocardial blood flow decreased significantly in the central ischemic regions of both groups $(p<0.01)$. There was no change in blood flow in the normal region or in the functional border zone with occlusion prior to drug infusion. There was no significant difference between blood flow in the normal zone and in the functional border zone in either group.

With infusion of phenylephrine, subendocardial blood flow in the central ischemic zone was not changed relative to occlusion alone. However, with infusion of this agent, a significant increase was noted in both the normal zone $(p<0.05)$ and the functional border zone $(p<0.05)$. There was no significant difference between blood flow in the normal zone and the functional border zone.

During nitroprusside administration, subendocardial blood flow was unaffected in the central ischemic zone or functional border zone compared to occlusion alone. Although nitroprusside resulted in a decrease in blood flow to the normal zone when
Table III. Regional left ventricular function in 16 dogs

\begin{tabular}{|c|c|c|c|}
\hline & \multicolumn{3}{|c|}{ Wall thickening $(\% \pm S E M)$} \\
\hline & Control & Occlusion & $\begin{array}{c}\text { Occlusion }+ \\
\text { drug }\end{array}$ \\
\hline \multicolumn{4}{|c|}{ Phenylephrine group } \\
\hline Normal zone & $57.4 \pm 5.1$ & $61.2 \pm 5.0$ & $62.5 \pm 8.9$ \\
\hline $\begin{array}{l}\text { Functional } \\
\text { border zone }\end{array}$ & $43.7 \pm 4.7$ & $13.1 \pm 3.6^{*}$ & $17.4 \pm 3.4^{*}$ \\
\hline $\begin{array}{l}\text { Central } \\
\text { ischemic } \\
\text { zone }\end{array}$ & $37.6 \pm 2.6$ & $-4.9 \pm 4.0^{*}$ & $-5.6 \pm 3.0^{*}$ \\
\hline \multicolumn{4}{|c|}{ Nitroprusside group } \\
\hline Normal zone & $44.6 \pm 4.7$ & $57.4 \pm 3.0^{*}$ & $56.4 \pm 4.8$ \\
\hline $\begin{array}{l}\text { Functional } \\
\text { border zone }\end{array}$ & $43.4 \pm 3.6$ & $17.8 \pm 4.5^{*}$ & $15.9 \pm 1.7^{*}$ \\
\hline $\begin{array}{l}\text { Central } \\
\text { ischemic } \\
\text { zone }\end{array}$ & $36.0 \pm 3.7$ & $-8.7 \pm 4.6^{*}$ & $-13.0 \pm 2.8^{*}$ \\
\hline
\end{tabular}

${ }^{*} p<0.01$ compared to control.

compared to occlusion alone $(p<0.05)$, normal zone blood flow was not significantly different from blood flow in the functional border zone. The circumferential extent of hypoperfusion was not significantly altered by infusion of either drug.

Regional left ventricular function (Table III, Figs. 4 and 5). Immediately after coronary artery occlusion, localized wall motion and wall thickening abnormalities were seen in the two-dimensional echocardiograms from each animal. In both groups, following left circumflex artery occlusion, there was a tendency for wall thickening to increase in the normal zone whereas wall thickening decreased in the functional border zone $(p<0.01)$ and the central ischemic zone $(p<0.01)$. The circumferential extent of wall thickening abnormality during coronary occlusion alone was similar in both groups $(161 \pm 17$ degrees for the phenylephrine group and $156 \pm 13$ degrees for the nitroprusside group).

Following administration of phenylephrine, no significant change in wall thickening was seen in the normal zone compared to baseline or occlusion values. In the central ischemic zone, the dyskinesis noted at occlusion was not altered by phenylephrine infusion, nor was the wall thickening abnormality in the functional border zone altered by infusion of this drug. Likewise, the extent of wall thickening dysfunction was the same at occlusion compared to occlusion plus infusion of phenylephrine. This circumferential extent of dysfunction was consistently larger than the extent of hypoperfusion, and the amount by which these two zones differed was not altered with phenylephrine infusion compared to 
occlusion alone. Therefore the size of the functional border zone during phenylephrine infusion $(32 \pm 10$ degrees) was not significantly changed from coronary occlusion alone ( $37 \pm 10$ degree, $p=n s$ ). The degree of dysfunction with occlusion alone was not changed by superimposing the phenylephrine infusion $(90 \pm 21 \%$ relative to occlusion alone, $p=\mathrm{ns})$.

In the nitroprusside group, the slight increase in wall thickening in the normal zone was not significantly changed during the infusion compared with occlusion alone. The wall thickening abnormalities in the central ischemic zone and the functional border zone were not changed with nitroprusside. In addition, the extent of dysfunction was not significantly changed. The circumferential extent of functional abnormality was larger than the extent of hypoperfusion and the amount by which these two zones differed was not altered with infusion of nitroprusside compared to occlusion alone. Thus the size of the functional border zone during nitroprusside infusion ( $22 \pm 11$ degrees) was not significantly changed compared with occlusion alone $(36 \pm 16$ degrees, $p=n s$ ). The degree of dysfunction was not altered by infusion of this drug $(100 \pm 8 \%$ for nitroprusside relative to occlusion alone).

\section{DISCUSSION}

A number of investigators have demonstrated $^{1-9,16-21}$ that contractile dysfunction extends beyond the perimeters of the ischemic area during acute coronary occlusion. Several studies ${ }^{2-5,8,9,17}$ have used sonomicrometers to identify and further characterize regional dysfunction lateral to the perfusion border. A number of other studies ${ }^{1,6,7,19-21}$ have taken advantage of two-dimensional echocardiography as a means of evaluating left ventricular function in complete cross section. With the use of this latter technique in conjunction with pathologic data, several investigators ${ }^{18-21}$ have reported that the extent of functional abnormality consistently overestimates infarct size. This observation is supported by work in our laboratory ${ }^{1}$ and by others ${ }^{6,7}$ who related functional parameters to measurements of blood flow. The present study extends our previous work to further characterize the functional border zone in the setting of increased or decreased afterload by the use of two-dimensional echocardiography.

Our results indicate that hemodynamically important alterations in afterload dn not nroduce a major change in circumferential flow-function relationships nor change the size of the functional border zone. Wall thickening in the functional border zone neither improved with afterload reduction nor dete- riorated with afterload increases. This suggests that the myocardium that is nonischemic but dysfunctional is not affected in a significant manner by simple load-altering maneuvers. Furthermore, our results indicate that the complex relationship between flow and function in the regionally ischemic heart is relatively fixed early following coronary occlusion.

Preliminary results from Sakai et al. $^{8}$ are in agreement with our observations. They used sonomicrometers placed on the epicardial surface to measure regional function by noting segment shortening parallel to the perfusion boundary. In their pig model, an increase in afterload was produced by aortic constriction during periods of left anterior descending artery occlusion. They noted that the relative reduction in shortening close $(5 \mathrm{~mm})$ to the perfusion boundary was the same as that in segments located a greater distance $(15 \mathrm{~mm})$ away after elevation of systolic blood pressure. Consequently, they concluded that afterload affects nonischemic myocardium uniformly without changing the lateral extent of nonischemic dysfunction. A recent report by Gallagher et al. ${ }^{9}$ also concurs with our results. They used sonomicrometers to measure systolic wall thickening in open-chest, anesthetized dogs and radioactive microspheres to assess myocardial blood flow. By constricting the aorta, they increased peak systolic blood pressure approximately $50 \%$ during left circumflex artery occlusion. The extent of nonischemic dysfunction was estimated by sigmoid curves fit to the data. They found that the functional border zone so defined averaged $26 \pm 6$ degrees during coronary artery occlusion alone and did not change significantly with aortic constriction $(29 \pm$ 11 degrees), leading to the conclusion that elevations in afterload do not increase the size or relative severity of the functional border zone.

The present study complements and extends the work of these investigators by the use of twodimensional echocardiography. With this technique, full cross sections of the left ventricle were examined, thereby obviating the limited global resolution inherent in the use of sonomicrometers. Furthermore, though previous studies on the effects of increases in afterload support our results, the effects of decreases in blood pressure have not been investigated previously in the context of nonischemic dysfunction.

Sodium nitroprusside is a potent vasodilator that reduces afterload and, to a certain extent, preload. We hypothesized that this effect would reduce stress concentration, ${ }^{22,23}$ or tethering ${ }^{4,24}$ at the margins of the ischemic area, resulting in a decrease in the 
lateral extent of the border zone. However, in our study no change in the functional border zone was observed. The lack of functional improvement may be related to the trend toward decreased subendocardial blood flow in the functional border zone, producing mild relative ischemic dysfunction. We think a more likely mechanism may be that the small decrease in preload, documented by a decrease in left ventricular end-diastolic area, offset the potential functional improvement that may occur with afterload reduction.

Alterations of left ventricular function by afterload reduction in the setting of myocardial ischemia have been previously investigated but not specifically in the context of the functional border zone. Although early studies ${ }^{25-27}$ that used segment length shortening suggested an increase in systolic function in regionally ischemic myocardium after vasodilator infusion, more recent studies ${ }^{28,29}$ that used echocardiographic techniques have indicated no change in wall motion or thickening in the central ischemic zone. Furthermore, Komer et al. ${ }^{29}$ examined function in the zone between the central ischemic zone and normally perfused myocardium and noted no significant improvement in regional function with the infusion of nitroglycerin. Gueret et al., ${ }^{30}$ however, made the observation that variable responses to the vasodilator may occur in remote regions with less severe degrees of ischemia. This may help explain some of the apparent discrepancies among previous studies. The present study indicates that vasodilator therapy does not significantly alter function in myocardium that is severely ischemic.

Phenylephrine is a potent alpha-adrenergic agonist that has little effect on the beta receptors of the heart. Previous studies ${ }^{31,32}$ concerning the effects of increased afterload on the ischemic myocardium suggest that increased coronary collateral flow may occur. In our study, however, there was no evidence of increased collateral flow in the central ischemic region. The lateral extent of the functional border zone did not increase with phenylephrine and regional function within this area did not deteriorate. This observation may have been a result of the modest increase in subendocardial blood flow in the functional border zone noted during drug infusion (Table II). An alternate explanation may be that a small but significant inotropic enhancement occurred that was sufficiently great to counterbalance the effect of elevated afterload to decrease wall thickening in the border zone and control regions.

One mechanism proposed to explain the phenomenon of nonischemic dysfunction is the concept of tethering. ${ }^{4,16,24}$ This theory implies that the motion in nonischemic muscle is mechanically restricted by dyskinetic muscle in the adjacent ischemic area. A more rigorous mathematical concept has has been proposed by Bogen et al., ${ }^{22,23}$ and is termed stress amplification. Based on modeling the left ventricle as a sphere, they calculated the degree of stress concentration at the interface between infarcted and noninfarcted myocardium. This stress was maximal at the interface and normal function was predicted to recover logarithmically over 45 degrees of circumference or less which, in fact, corresponded closely with our in vivo results. An alternative explanation for the lack of change in the extent of the functional border zone in either intervention group may be that manipulation of afterload was not sufficient to alter the local forces that lead to nonischemic dysfunction. It may be that the small changes in regional stress that were produced by our afterload changes were insufficient to alter the distance that stress amplification extends from the ischemic-nonischemic interface.

In view of the known responses of myocardial function to afterload changes, it was somewhat surprising to us to observe no significant change in wall thickening in the normal, nonischemic myocardium following nitroprusside or phenylephrine infusion. However, other investigators ${ }^{27,28,30}$ have made similar observations in models of regional myocardial ischemia following manipulations of afterload. There are several possible explanations for this lack of change. First, it is possible that the compensatory augmentation of remote nonischemic function in the setting of myocardial ischemia has reached its load reserve so that only changes in inotropic state will increase wall thickening. In this regard, experiments from our laboratory that used dobutamine infusion in a similar animal model have demonstrated significant increases in wall thickening in the remote, normal myocardium compared to coronary occlusion alone. ${ }^{33}$ Second, it is possible that global hemodynamic changes masked the improvement in regional function resulting in no apparent regional functional change. For example, with nitroprusside, the improvement of wall thickening may have been offset by the simultaneous global preload reduction. This interpretation is supported by an increase in wall thickening following correction for left ventricular end-diastolic area. In the case of phenylephrine, an afterload effect may have been offset by a mild inotropic effect. Finally, it is possible that any functional change with loading alteration is only apparent in more remote nonischemic myocardium. In this regard, a study by Gueret et al. ${ }^{30}$ that used two dimensional echocardiography found a func- 
tional response to nitroprusside only in a crosssectional plane more remote from the central ischemic area. It may be that the midpapillary muscle level, which was used in our study, may not have adequately reflected the global response to pharmacologic intervention in the setting of acute ischemia.

In conclusion, our data support the concept of a functional border zone representing a discrete region of normally perfused but dysfunctional muscle adjacent to ischemic myocardium. Alterations in afterload large enough to produce significant hemodynamic changes in arterial blood pressure did not affect the circumferential flow-function relationships or the extent of the functional border zone. These data suggest that in the setting of severe myocardial ischemia alterations in afterload do not result in improvement of ischemic or nonischemic, dysfunctional myocardium. Thus pharmacologic manipulations of afterload during acute regional ischemia may produce global hemodynamic effects through the action of afterload on remote, nonischemic, normally functioning myocardium.

We appreciate the excellent technical assistance of Diane Pace, BS, and Lisa Krause, MA, in the completion of these studies.

\section{REFERENCES}

1. Buda AJ, Zotz RJ, Gallagher KP. Characterization of the functional border zone around regionally ischemic myocardium using circumferential flow-function maps. J Am Coll Cardiol 1986;8:150.

2. Gallagher KP, Gerren RA, Stirling MC, Choy M, Dysko RC, McManimon TB, Dunham WR. The distribution of functional impairment across the lateral border zone of acutely ischemic myocardium. Circ Res 1986;58:570.

3. Cox DA, Vatner SF. Myocardial function in areas of heterogeneous perfusion after coronary artery occlusion in conscious dogs. Circulation 1982;66:1154.

4. Guth BD, White FC, Gallagher KP, Bloor CM. Decreased wall thickening in myocardium adjacent to ischemic zones in conscious swine during brief coronary artery occlusion. AM HEART J 1984;107:458.

5. Sakai K, Watanabe K, Millard RW. Defining the mechanical border zone: a study in the pig heart. Am J Physiol 1985; 249:H88.

6. Lima JAC, Becker LC, Melin JA, Lima S, Kallman CH, Weisfeldt ML, Weiss JL. Impaired thickening of nonischemic myocardium during acute regional ischemia in the dog. Circulation 1985;71:1048.

7. Homans DC, Asinger R, Elsperger KJ, Erlien D, Sublett E, Mikell F, Bache RJ. Regional function and perfusion at the lateral border of ischemic myocardium. Circulation 1985; 71:1038.

8. Sakai K, Watanabe K, Millard RW. Effects of ventricular afterload on areas surrounding transmural ischemic myocardium [Abstract]. Fed Proc 1984;43:420.

9. Tallaghar KD Ning X, Serron DA, Diahe DH, Dunham WR. Effect of aortic constriction on the functional border zone. Am J Physiol 1987;252:H826.

10. Heymann MA, Payne BD, Hoffman JIE, Rudolph AM. Blood flow measurements with radionuclide-labeled particles. Prog Cardiovasc Dis 1977;20:55.

11. Weiss RJ, Buda AJ, Pasyk S, O'Neill WW, Keyes JW Jr, Pitt
B. Non invasive quantification of jeopardized myocardial mass using two-dimensional echocardiography and thallium201 tomography. Am J Cardiol 1985;52:1340.

12. Zotz R, Meyer CR, Delp EJ, Bookstein FL, Buda AJ. Reliability of measurements from two-dimensional echocardiographic images using a cardiac phantom [Abstract]. Clin Res 1985;33:24A.

13. Murdock PH Jr, Harlan DH, Morris JJ, Pryor WW, Cobb FR. Transitional blood flow zones between ischemic and non-ischemic myocardium in the awake dog. Analysis based on distribution of intramural vasculature. Circ Res 1983; $52: 451$.

14. Buda AJ, Zotz RJ, Pace DP, Krause LC. Comparison of two-dimensional echocardiographic wall motion and wall thickening abnormalities in relation to the myocardium at risk. АM HEART J 1986;111:587.

15. Wallenstein S, Zucker CL, Fleiss JL. Some statistical methods useful in circulation research. Circ Res 1980;47:1.

16. Kerber RE, Marcus ML, Ehrhardt J, Wilson R, Abboud FM. Correlation between echocardiographically demonstrated segmental dyskinesis and regional myocardial perfusion. Circulation 1975;52:1097.

17. Gallagher KP, Kumada T, Koziol JA, McKown MD, Kemper WS, Ross J Jr. Significance of regional wall thickening abnormalities relative to transmural myocardial perfusion in anesthetized dogs. Circulation 1980;62:1266.

18. Wyatt HL, Meerbaum S, Heng MK, Rit J, Gueret P, Corday E. Experimental evaluation of the extent of myocardial dyssynergy and infarct size by two-dimensional echocardiography. Circulation 1981;63:739.

19. Nieminen M, Paris A, O'Boyle JE, Folland ED, Khuri $S$, Kloner RA. Serial evaluation of myocardial thickening and thinning in acute experimental infarction; identification and quantification using two-dimensional echocardiography. Circulation 1982;66:174.

20. Pandian N, Koyanagi S, Skorton D, Collins S, Marcus M, Kerber R. Relations between two-dimensional echocardiographic wall thickening abnormalities, myocardial infarct size and coronary risk area in normal and hypertrophied myocardium in dogs. Am J Cardiol 1983;52:1318.

21. Taylor AL, Kieso RA, Melton J, Hite P, Pandian NG, Kerber RE. Echocardiographically detected dyskinesis, myocardial infarcts and coronary risk region relationships in reperfused canine myocardium. Circulation 1985;71:1292.

22. Bogen DK, Rabinowitz SA, Needleman A, McMahon TA, Abelmann WH. An analysis of the mechanical disadvantage of myocardial infarction in the canine left ventricle. Circ Res 1980;47:728.

23. Bogen DK, Needleman A, McMahan TA. An analysis of myocardial infarction. The effect of regional changes in contractility. Circ Res 1984;55:805.

24. Force T, Kemper A, Perkins L, Gilford M, Cohen C, Parisi AF. Overestimation of infarct size by quantitative twodimensional echocardiography: the role of tethering and of analytic procedures. Circulation 1986;73:1360.

25. de Luz PL, Forrester JS, Wyatt HL, Tyberg JV, Chagrasulis R, Parmley WW, Swan HJC. Hemodynamic and metabolic effects of sodium nitroprusside on the performance and metabolism of regional ischemic myocardium. Circulation 1975;52:400.

26. Theroux P, Franklin D, Ross J Jr, Kemper WS. Regional myocardial function during acute coronary artery occlusion and its modification by pharmacologic agents in the dog. Circ Res 1974;35:896.

27. Theroux P, Ross J Jr, Franklin D, Kemper WS, Sasayama S. Regional myocardial function in the conscious dog during acute coronary occlusion and responses to morphine, propranolol, nitroglycerin and lidocaine. Circulation 1976; 53:302.

28. Kerber RE, Martins JB, Marcus ML. Effect of acute ischemia, nitroglycerin and nitroprusside on regional myocardial thickening, stress and perfusion. Circulation 1979;60:121.

29. Komer RR, Edalji A, Hood WB. Effects of nitroglycerin on 
echocardiographic measurements on left ventricular wall thickness and regional myocardial performance during acute coronary ischemia. Circulation 1979;59:926.

30. Gueret P, Meerbaum S, Corday E, Uchiyama T, Wyatt HL, Broffman J. Differential effects of nitroprusside on ischemic and nonischemic myocardial segments demonstrated by computer-assisted two dimensional echocardiography. Am J Cardiol 1981;48:59.

31. Roan PG, Buja M, Saffer S, Izquierdo C, Hagler H, Duke B, Hillis LD, Willerson JT. Effects of systemic hypertension on ischemic and nonischemic regional left ventricular function in awake, unsedated dogs after experimental coronary occlusion. Circulation 1982;65:115.

32. Kerber RE, Marcus ME, Ehrhardt J, Abboud FM. Effect of increases in afterload on the systolic thickening of acutely ischemic myocardium. An experimental echocardiographic study. Acta Med Scand 1979;627:142.

33. Buda AJ, Zotz RJ, Gallagher KP. The effect of inotropic stimulation on normal and ischemic myocardium following coronary occlusion. Circulation 1987;76:163.

\title{
The effect of regional myocardial ischemia on
}

Doppler echocardiographic indexes of left

ventricular performance: Influence of heart rate, aortic blood pressure, and the size of the ischemic zone

\begin{abstract}
Doppler echocardiographic indexes of ascending aortic blood flow velocity have been found to be an effective method of assessing changes in left ventricular performance induced by myocardial lschemia in both experimental animal preparations and in patients. In oight opened-chest anesthetized dogs, we investigated the influence of heart rate, aortic blood pressure, and size of the ischemic zone on Doppler Indexes during regional myocardial ischemia. With control of mean aortic blood pressure and heart rate, transient coronary artery occlusion resulted in a statistically significant decllne in peak velocity and mean velocity when as little as $24 \%$ of left ventrlcular myocardlum was rendered lschemlc. However, when heart rate and mean aortic blood preseure were not controlled, significant declines in peak velocity and meen velocity occurred only with simultaneous two-vessel occlusions involving $>47 \%$ of left ventricular myocardium. Although transient coronary artery occlusions generally produced no significant change in heart rate in the absence of atrial pacing, significant declines in aortic blood pressure were observed. We conclude that Doppler Indexes of loft ventricular performance obtained during myocardial lechemla are influenced not only by the extent of myocardium rendered ischemic, but also by changes in mean eortic blood pressure. (AM HEART J 1988;116:953.)
\end{abstract}

David W. Mathias, MD, L. Samuel Wann, MD, Kiran B. Sagar, MD, and H. Sidney Klopfenstein, MD, PhD. Milwaukee, Wis., and Winston-Salem, N.C.

From the Department of Medicine, Medical College of Wisconsin, and the Departments of Medicine and Physiology, The Bowman Gray School of Medicine.

Supported in part by grants RO1 HL32228 and T32 HL07546, from the National Institutes of Health, National Heart, Lung, and Blood Institute, the American Heart Association of Wisconsin, and the Heath Foundation. Statistical analysis was supported in part by General Clinical Research Center Grant No. RR00058 (Raymond G. Hoffmann, PhD).

Received for publication Jan. 26, 1988; accepted June 1, 1988.

Reprint requests: $\mathrm{H}$. Sidney Klopfenstein, $\mathrm{MD}, \mathrm{PhD}$, Cardiology Division, The Bowman Gray School of Medicine, 300 So Hawthorne Rd., WinstonSalem, NC 27103.
The use of Doppler echocardiographic indexes of ascending aortic blood velocity is an effective, noninvasive method of assessing short-term changes in left ventricular performance. ${ }^{1-3}$ Earlier investigations $^{4-8}$ of aortic blood velocity, which used cathetertipped velocity probes in the setting of myocardial ischemia, have shown promise in detecting changes in left ventricular performance induced by temporary coronary artery occlusion and acute myocardial infarction in both conscious dogs and patients. 